\title{
某些现代生物中正构烷烃碳 同位素研究
}

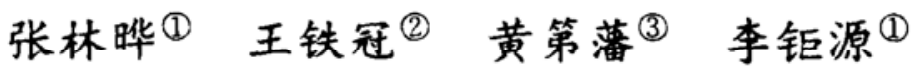 \\ 李祥臣(1) 单 梅 ${ }^{(1)}$ 王新洲 ${ }^{(1)}$ \\ (1)胜利石油管理局地质科学研究院, 东萼, 257015; (2)石油大学地球科学系, 北京 102200; \\ (3)石油勘探开发科学研究院地质研究所, 北京 100083)
}

摛要选择了对油气生成具有意义的各种现代生物进行热压模拟实验, 测定了不同生物体中 正构烷烃碳同位素值, 并研究了不同生物体中单个正构烷烃的同位素分布特征,该实验结果为 判别沉积有机质中正构烷烃的生物来源提供了重要线索.

\section{关键词 正构嫔烃 碳同位素 现代生物 热模拟 生物来源}

正构烷烃是烃源岩中分布最广泛的化合物,一般可占饱和烃馏份的 $50 \% \sim 80 \%$. 因此, 这部分化合物的生源意义对整个烃源岩的评价具有举足轻重的作用. 传统的观点认为, 碳数 $\left\langle\mathrm{C}_{22}\right.$ 的正构烷烃标志着菌㩰类低等水生生物脂肪酸的生源; 碳数 $>\mathrm{C}_{22}$ 的正构烷烃通常属于 高等植物上表皮蜡起源. 在大多数情况下, 上述观点具有一定的普遍意义, 并且被广泛应用于 烃源岩的评价中. 但人们对现代生物正构烷烃分布特征的研究表明, 高碳数正构烷烃的生源 具有多解性 ${ }^{[1]}$, 因此, 关于正构烷烃的生源意义已成为分子有机地球化学领域里令人困惑的 问题. 但是,单体烃碳同位素分析技术的发展,将有助于解决这方面的问题 ${ }^{22}$.

近来, 有关不同细菌和陆生植物叶类中单个正构烷烃碳同位素组成特征已有文献进行了 报道 ${ }^{[3,4]}$, 并论述了不同生物来源沉积有机质中正构烷烃碳同位素特征. 但与油气生成有着 密切关系的不同蕜类, 浮游动物等现代生物体中单个正构烷烃碳同位素的特征报道不多. 本 文选择了对生油具有意义的海洋浮游生物、淡水浮游生物、陆地草本和木本植物等 8 个具有代 表性的样品进行热压模拟实验, 系统研究了不同生物体中正构烷烃碳同位素的分布特征, 为探 讨沉积有机质中正构烷烃的生物来源提供依据.

\section{1 样品和方法}

用于研究的某些现代生物样品见表 1. 将粉碎好的样品取 $0.5 \sim 2 \mathrm{~g}$ 放入耐压玻璃管中, 抽真空封口后, 放在高压釜内, 将金内密封, 抽真空, 充氮加压后, 加温至 $320^{\circ} \mathrm{C}$, 釜内压力达到 155 大气压 (1 个大气压约等于 $\left.10^{5} \mathrm{~Pa}\right)$, 恒定 $64 \mathrm{~h}$ 后降温, 选择 $320 \mathrm{C}, 64 \mathrm{~h}$ 这一时温组合条件 大约相当于地质体中大量生油阶段.

样品取出抽提分离后获饱和烃. 饱和烃溶解在异辛烷溶液中, 加入粒状为 $0.5 \mathrm{~nm}$ 分子 笁, 在水浴中加热 $18 \mathrm{~h}$. 用氢氟酸破坏吸附了正构烷烃的 $0.5 \mathrm{~nm}$ 分子笁, 然后用正己烷萃取 正构烷烃,采用色谱-燃烧-同位素质谱仪(GC/IRMS)测定正构㜔烃碳同位素 ${ }^{[5]}$.

\section{2 正构烷烃分布特征}

生物样品模拟后正构烷烃分布特征见图 1. 由图 1 可见, 模拟后陆地植物样品均以高碳 
表 1 生物样品表

\begin{tabular}{|c|c|c|c|c|}
\hline 编号 & 取样地点 & 名称 & 注 & $\delta{ }^{13} \mathrm{C} / \%_{0}(\mathrm{PDB})$ \\
\hline 1 & 青禹海滨潮间带 & 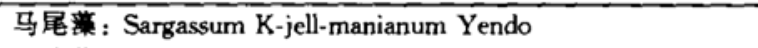 & 楬菓 & -18.5 \\
\hline 2 & & 石孔莼: Ulua pertusa Kjellm & 绿荣 & -19.0 \\
\hline 3 & 青舟海湾 & $\begin{array}{l}\text { 浮游动物: Sagitta crassa }(40.47 \%) \text {, Calanus sinicus } \\
(22.11 \%) \text {. Acartia spp }(29.60 \%)\end{array}$ & & -23.9 \\
\hline 4 & 海水培养 & 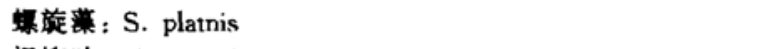 & 蓝菜 & - \\
\hline 5 & 东苔含践陆地 & 柽柳叶: Tamarix hispida & & -28.1 \\
\hline 6 & 东垫陆地碱滩 & 黄花蓠(?): Artemisia annua & & -28.7 \\
\hline 7 & 东营淡水渠 & 水绵: Spirogyra link & 绿萧 & -15.8 \\
\hline 8 & $\begin{array}{l}\text { 吉林双阳县地表下 } \\
\quad 40 \sim 130 \mathrm{~cm}\end{array}$ & $\begin{array}{l}\text { 泥炭土: 主要为松属、草本的禾本科等, 未见水生生物 (930 } \\
290 \mathrm{aBP} \text { ) }\end{array}$ & & -28.5 \\
\hline
\end{tabular}

数为主, 柽柳叶的主峰碳为 $n \mathrm{C}_{31}$, 黄花蓠为 $n \mathrm{C}_{28}$, 由松属、禾本科、菊科和栋属等陆地植物组成 的泥炭土的主峰碳为 $n \mathrm{C}_{27}$. 而水生生物的碳数分布却存在差异,一种是以 $\mathrm{C}_{17}$ 和 $\mathrm{C}_{19}$ 为主峰的 海洋浮游动物、绿藻石孔莼及淡水绿藻水绵, 而另一种是以 $\mathrm{C}_{25}$ 和 $\mathrm{C}_{29}$ 为主峰的海洋褐藻及海 水培养的螺旋藻。

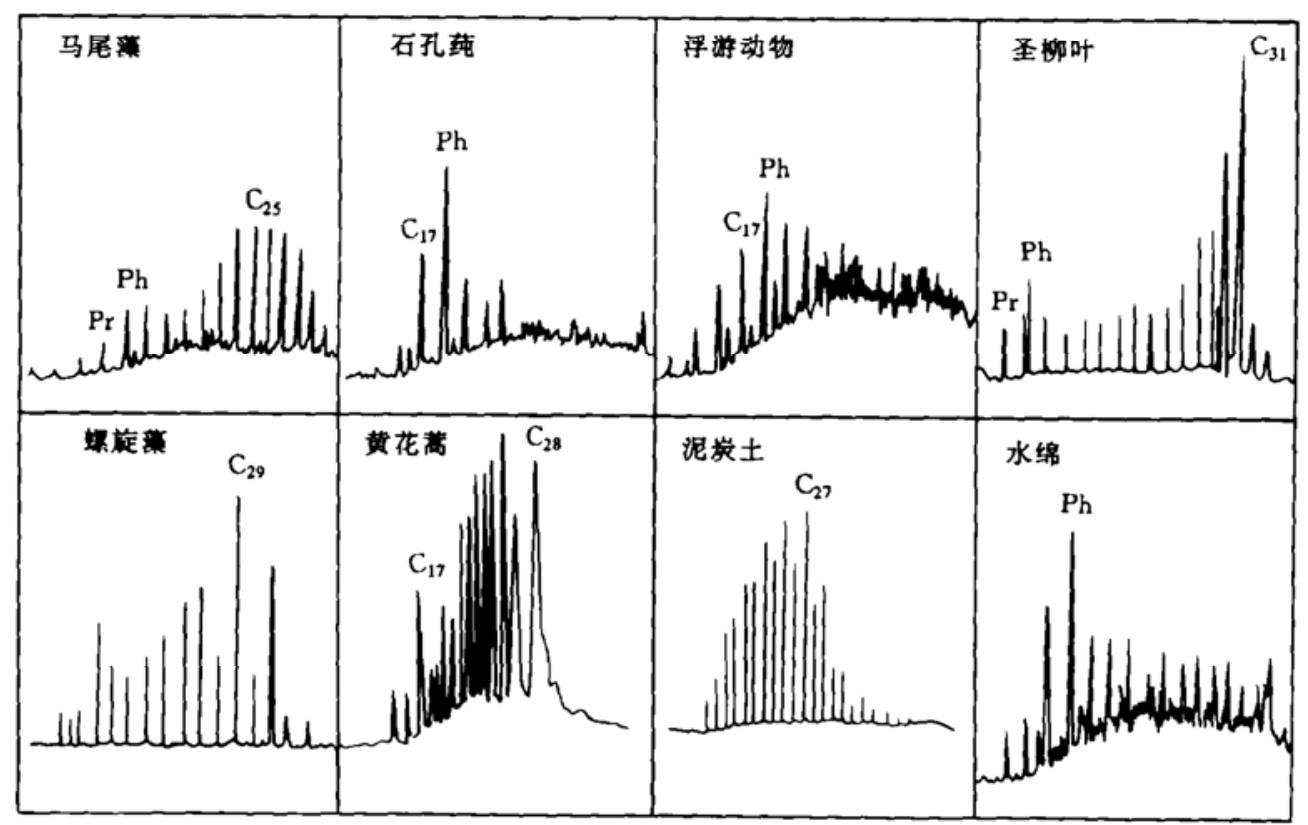

图 1 生物样品模拟后烧烃色谱图(据王新洲 1996 年改编)

\section{3 正构烷烃碳同位素组成}

不同生物样品的正构烷烃碳同位素组成见图 2. 由图 2 可见, 来源于陆地植物的黄花芳、 柽柳叶、泥炭土其正构烷烃碳同位素富集 ${ }^{12} \mathrm{C}, \delta{ }^{13} \mathrm{C}$ 均小于 $-30 \%$ 。同位素曲线较平滑, 但泥 炭土的 $\delta{ }^{13} \mathrm{C}$ 在碳数 $\mathrm{C}_{28} \sim \mathrm{C}_{31}$ 时变轻, 而后又变重.

水生生物正构烷烃的碳同位素分异明显. 螺旋藻正构烷烃碳同位素在 $\mathrm{C}_{21}$ 以前随碳数增 加碳同位素变轻, $\mathrm{C}_{21} \sim \mathrm{C}_{26}$ 随碳数增加碳同位素略变重, 但总体变化平缓, 奇碳数与偶碳数的 
$\delta{ }^{13} \mathrm{C}$ 值差异不大. $\mathrm{C}_{26}$ 以后, 奇碳数与偶碳 数的 $\delta{ }^{13} \mathrm{C}$ 呈明显的锯齿状, 奇碳数的 $\delta{ }^{13} \mathrm{C}$ 比相邻偶碳数 $\delta{ }^{13} \mathrm{C}$ 重 $1.48 \% \sim 4.09 \%$, 并 随碳数的增加富集 ${ }^{13} \mathrm{C}$; 水绵正构烷烃碳同位 素在 $\mathrm{C}_{22}$ 以前奇碳数与偶数 $\delta{ }^{13} \mathrm{C}$ 呈锯齿状, 奇碳数比相邻偶碳数 $\delta{ }^{13} \mathrm{C}$ 重 $0.73 \%$ $3.96 \%, \mathrm{C}_{22}$ 以后锯齿状消失, 但随着碳数的 增加, 碳同位素迅速变轻, 大于 $\mathrm{C}_{28}$ 碳同位素 略变重. 马尾藻 $\mathrm{C}_{21}$ 以前随碳数增加碳同位 素变重, $\mathrm{C}_{21} \sim \mathrm{C}_{25}$ 随碳数增加碳同位素迅速变 轻. $\mathrm{C}_{25} \sim \mathrm{C}_{30}$ 变化平缓. 大于 $\mathrm{C}_{30}$ 碳同位素 随碳数增加变重; 石孔莼与浮游动物具有相 似的碳同位素变化特征, $\mathrm{C}_{28}$ 以前随碳数增加 碳同位素变轻, 其后随碳数的增加又变重.

水生生物与陆地植物相比富集 ${ }^{13} \mathrm{C}$, 见表 1. 两类生物模拟后其正构烷烃碳同位素与 生物原样相比富集 ${ }^{12} \mathrm{C}$, 但水生生物的正构烷 烃碳同位素比陆地植物正构烷烃碳同位素富 集 ${ }^{13} \mathrm{C}$. 两类生物产生同位素差异的原因, 可
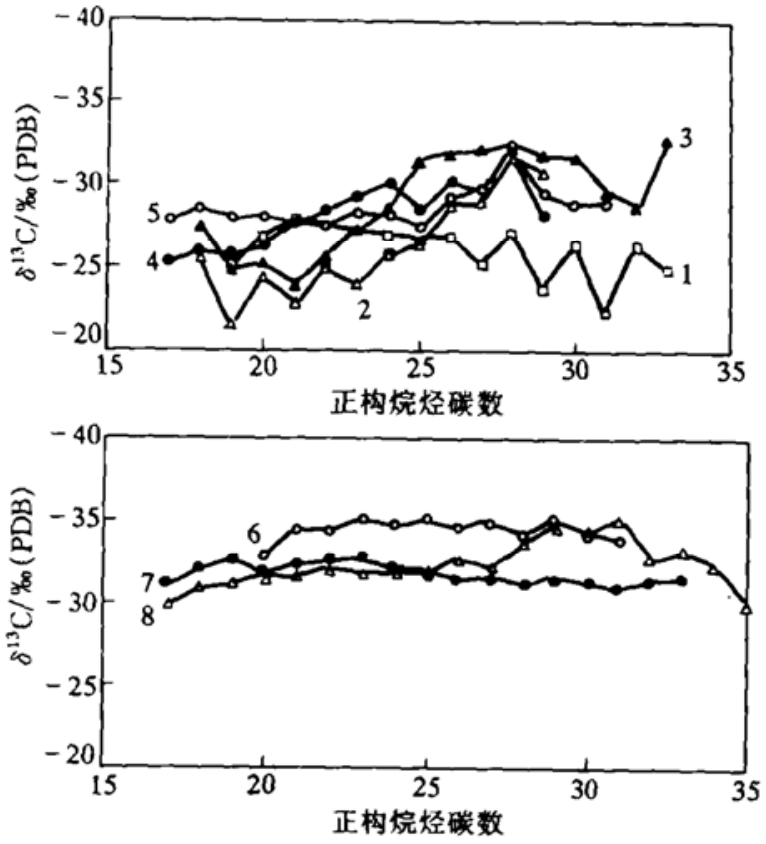

图 2 不同生物样品正构焢烃碳同位素类型曲线

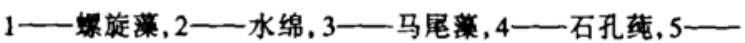

浮游动物, 6一黄花蓄, 7一柽柳叶, 8一泥炭土 能是它们在进行光合作用时利用了不同的碳源, 水生生物光合作用过程中利用的碳源为水中 的重碳酸根 $\mathrm{HCO}_{3}^{-}$, 而陆地植物光合作用的碳源为大气中的 $\mathrm{CO}_{2}$.

\section{4 结论}

现代生物的热压模拟实验表明, 陆生植物的正构烷烃碳数分布以高碳数为主,而水生生物 正构焢烃的碳数分布却存在低碳数和高碳数为主峰的两种分布模式.

各种生物体中正构烷烃的碳同位素分布特征，总体来说，陆地植物富集 ${ }^{12} \mathrm{C}$, 而水生生物 富集 ${ }^{13} \mathrm{C}$. 来源于陆地植物的正构烷烃碳同位素曲线分布平滑.

来源于水生生物的正构烷烃碳同位素分异明显. 螺旋藻正构烷烃随碳数的增加碳同位素 变重. 其他 4 种水生生物的正构烷烃碳同位素 (马尾藻、水绵、石孔莼、浮游动物), 总体来说, 小于 $\mathrm{C}_{28}$ 随碳数增加变轻, 大于 $\mathrm{C}_{28}$ 随碳数增加变重. 与海水有关的水生生物中正构烷烃的碳 同位素具有三段分布特征, 即低碳数的碳同位素较重, 随碳数增加同位素变轻, 又变重. 淡水 㩰和海水培养的螺旋落的正构烷烃碳同位素曲线分别在低碳数和高碳数出现明显的锯齿状, 即奇碳数与相邻的偶碳数相比富集 ${ }^{13} \mathrm{C}$. 生物被埋藏后的早期成岩作用及成岩热力作用都会 使原始有机质产生同位素分馏, 但经历同位素分馏后的沉积有机质的碳同位素仍然对原始有 机质有较强的继承性 ${ }^{[6]}$. 因此, 现代生物的碳同位素特征为研究烃源岩的母质来源提供了重 要的线索.

致谢本工作为中国石油天然气总公司“九五”科学技术工程研究(批准号: 95-31-03-11-1) 资助项目. 


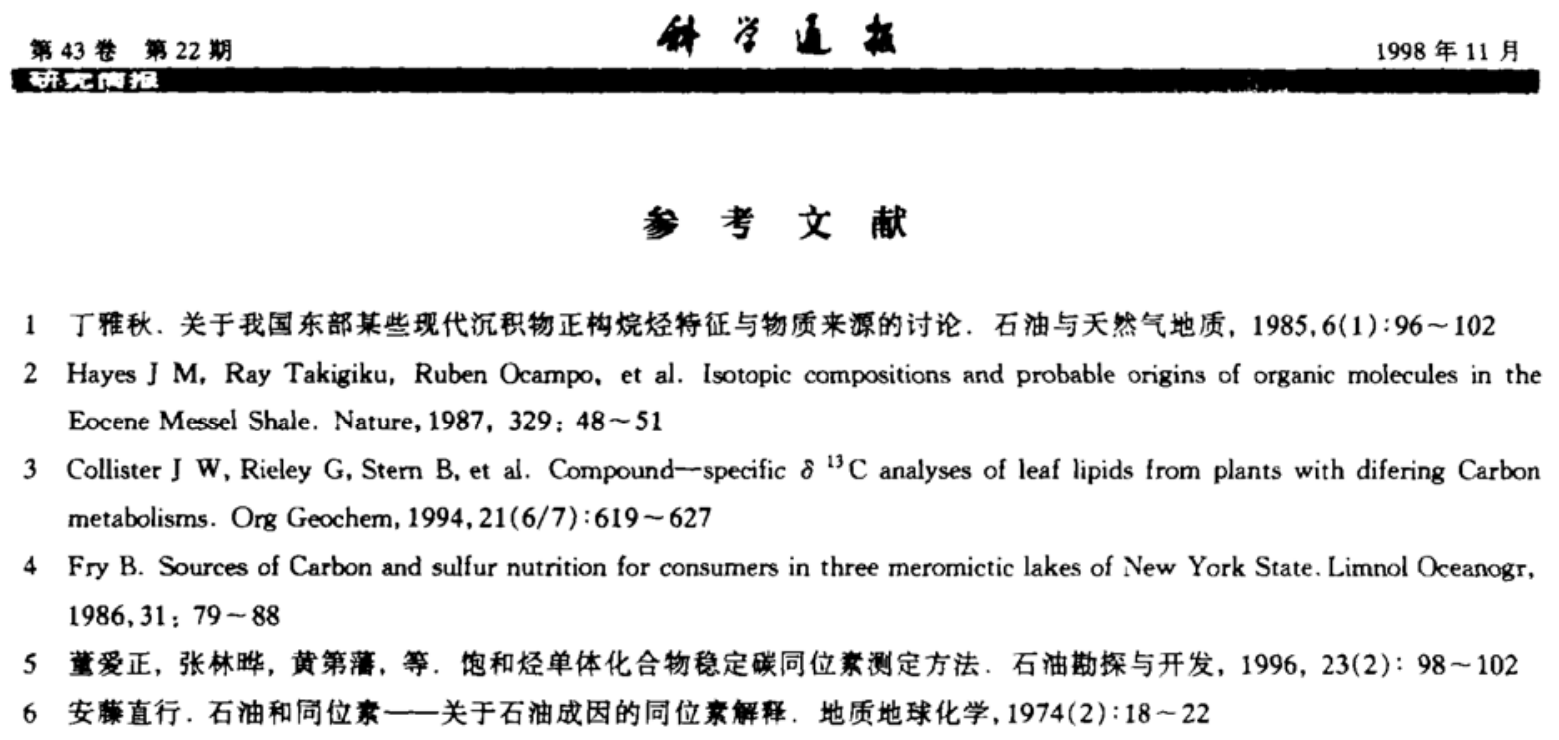

(1998-02-10 收稿, 1998-05-04 收修改稿)

\title{
黄土丘陵区土地利用结构对 土壤养分分布的影响
}

傅伯杰 马克明 周华峰 陈利顶

(中国科学院生态环境研究中心, 北京 100085)

\begin{abstract}
摘要 选取黄土丘陵坡地 4 种已持续 15 余年的代表性土地利用结构类型, 研究不同土地利用 结构对士壤养分分布的影响. 从梁底到梁顶, 土地利用组合分别为: 草地一坡耕地一林地、坡耕 地一草地一林地、梯田-草地一林地和坡耕地一林地一草地。通过测定土壤全氮、全磷、有效氮、有效磷 和有机质, 结果分析发现: 坡业地-草地一林地和梯田-草地一林地类型具有较好的土壤养分保持 能力.
\end{abstract}

\section{关䰹词 黄土丘陵区 土地利用结构 土壤萧分 土壤僈蚀}

土地利用是影响元素分布的重要因素, 它的变化可引起许多自然和生态过程的变化,如土 壤状况、径流、侵蚀和生物多样性 ${ }^{[1]}$. 黄土丘陵区土壤侵蚀和养分流失的主要原因之一是不 合理的土地利用 ${ }^{[2]}$, 因此, 合理利用土地是该区域的研究重点. 土地适宜性评价将土地的自 然特征和经济条件相结合, 提出了土地的适宜利用类型, 但未考虑土地利用结构和生态过程 之间的相互关系 ${ }^{[3]}$. 本项研究选择黄土丘陵坡地上 4 种典型的土地利用结构类型, 研究不同 土地利用结构对土壤养分分布的影响, 提出合理的土地利用配置, 对土地评价研究进行补充和 深化.

\section{1 研究区域特征}

研究区域为延安市羊圈沟流域 $\left(36^{\circ} 42^{\prime} \mathrm{N}, 109^{\circ} 31^{\prime} \mathrm{E}\right)$, 距市区 $14 \mathrm{~km}$, 面积 $2.02 \mathrm{~km}^{2}$. 区 域地貌类型为黄土梁和黄士沟, 流域内从梁顶到沟底的最大高差为 $225 \mathrm{~m}$, 沟谷密度为 $2.74 \mathrm{~km} / \mathrm{km}^{2}$, 属典型黄土丘陵沟檠区. 流域内土壤以黄绵土为主, 土壤结构为粉质壤土, 抗 